\title{
LXVI. On the electrical charge of the active deposit of actinium
}

\section{Sidney Russ}

To cite this article: Sidney Russ (1908) LXVI. On the electrical charge of the active deposit of actinium , Philosophical Magazine Series 6, 15:90, 737-745, DOI: $10.1080 / 14786440809463813$

To link to this article: http://dx.doi.org/10.1080/14786440809463813

曲 Published online: 16 Apr 2009.

Submit your article to this journal $\pi$

Џ Article views: 2

Q View related articles $\sqsubset$ 
6 . The square root of the percentage differences of ionization, due to a reversal of potential of the radiator, is inversely proportional to the secondary radiation from the radiator. This is a rough approximation for radiators of equal areas made of different substances.

\section{McGill University, Montreal,} February 1908.

\section{Note added 25th April, 1908.}

In this paper I have upheld the old view that the secondary rays due to radium are not merely scattered primary. The experiments of H. W. Schmidt (Pliys. Zeit. June 1,1907 ) have to some extent weakened this theory. But the same observer has also shown that the $\beta$ particle does not lose speed in passing through matter; and, if that is the case, the secondary electrons should have the same velocity as the primary; and they have not. Again, $\gamma$ rays (we will suppose them to be æther pulses) give rise to secondary rays with velocities nearly equal to those of the secondary rays due to $\beta$ particles. There seems no reason to suppose that the $\beta$ rays could not cause the same projection of electrons from the atoms of the secondary radiator which we know that the $\gamma$ rays cause. It is true that the view, advocated by Bragg, of the material nature of the $\gamma$ rays is not out of harmony with observed facts; and, if that theory is correct, we may regard all secondary radiations, consisting of electrons with high velocities, as scattered primary rays.

\section{On the Electrical Charge of the Active Deposit of Actinium. By Sidnex Ross, Demonstrator in Physics, Manchester University*.}

$\mathbf{E}$ XPERIMENTS by several observers have shown that the active deposit of Thorium is aimost entirely directed to a negative electrode.

If into a vessel containing thorium emanation two wires be inserted, one charged negatively, the other positively, the amount of active deposit obtained on the negative wire is more than one hundred times that on the positive; this number, however, shows a considerable reduction if the pressure in the vessel is diminished to a few millimetres.

* Communicated by Prof. E. Rutherford, F.R.S. 
While working along similar lines with Actinium an exactly opposite effect was observed. Under the conditions of these experiments the activity of the negative was only twice that of the positive pole at atmospheric pressure, this ratio being increased to twenty-two on reducing the pressure to a few millimetres. (Phil, Mag. May 1908.)

It was found, however, that by varying the experimental arrangements, the activity of the negative electrode could be made to vary from twice to more than a hundred times that of the positive electrode, without altering the pressure. It appears from the observations to be described, that the variable which determines the electrical charge of the carriers of the active matter, is the distance which they travel before reaching the electrode. If this distance be very small (a few millimetres) the particles are almost completely directed to the negative pole, the ratio mentioned above therefore being very large; as the distance of travel is increased this ratio shows a marked diminution.

The experiments indicate that the collisions of the active deposit particles with the gas molecules or ions with which they are mixed, determine the sign of the electrical charge which they exhibit.

\section{Methods of Experiment.}

The first experiments, which have already been partly described in the paper referred to above, were made in the following inanner.

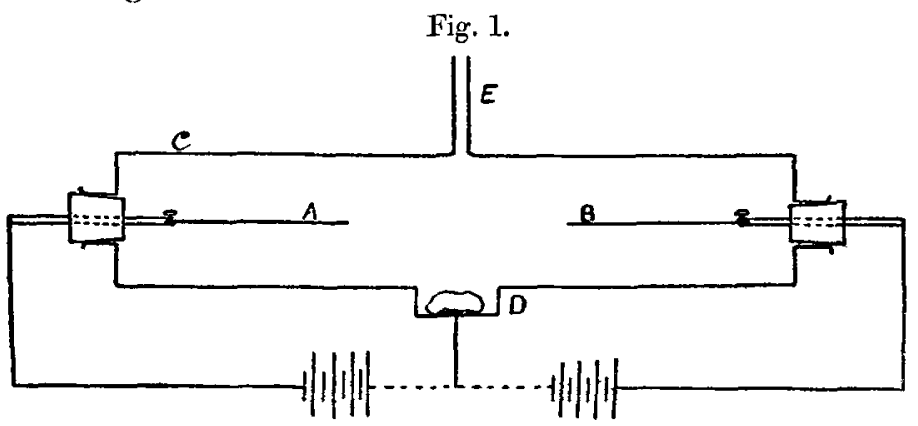

Two thin brass wires (A and B, fig. 1) $7.5 \mathrm{cms}$ long and $.7 \mathrm{~mm}$. diameter and $4 \mathrm{cms}$. apart, were made to lie along the axis of a brass tube C $30 \mathrm{cms}$. long and $4 \cdot 2 \mathrm{cms}$. diameter. This tube was fitted with a small capsule D into which was placed a small quantity of a preparation of actinium.

The wire $A$ was connected to the positive and $B$ to the 
negative pole of a battery of 320 volts, the brass tube being connected to the mid-point.

The exit-tube $\mathrm{E}$ could be connected to a Fleuss pump and a set of tubes containing calcium chloride and cotton-wool, thus ensuring a supply of dry and dust-free air.

The wires were exposed usually for about two hours, when they were removed and their activities compared by measuring the saturation currents, which they separately produced in a cylinder connected to an electrometer.

Observations were made for pressures between $2 \mathrm{mms}$. and $76 \mathrm{cms}$. of mercury. The numerical results are collected in Table I. and shown graphically in fig. 2.

Fig. 2.

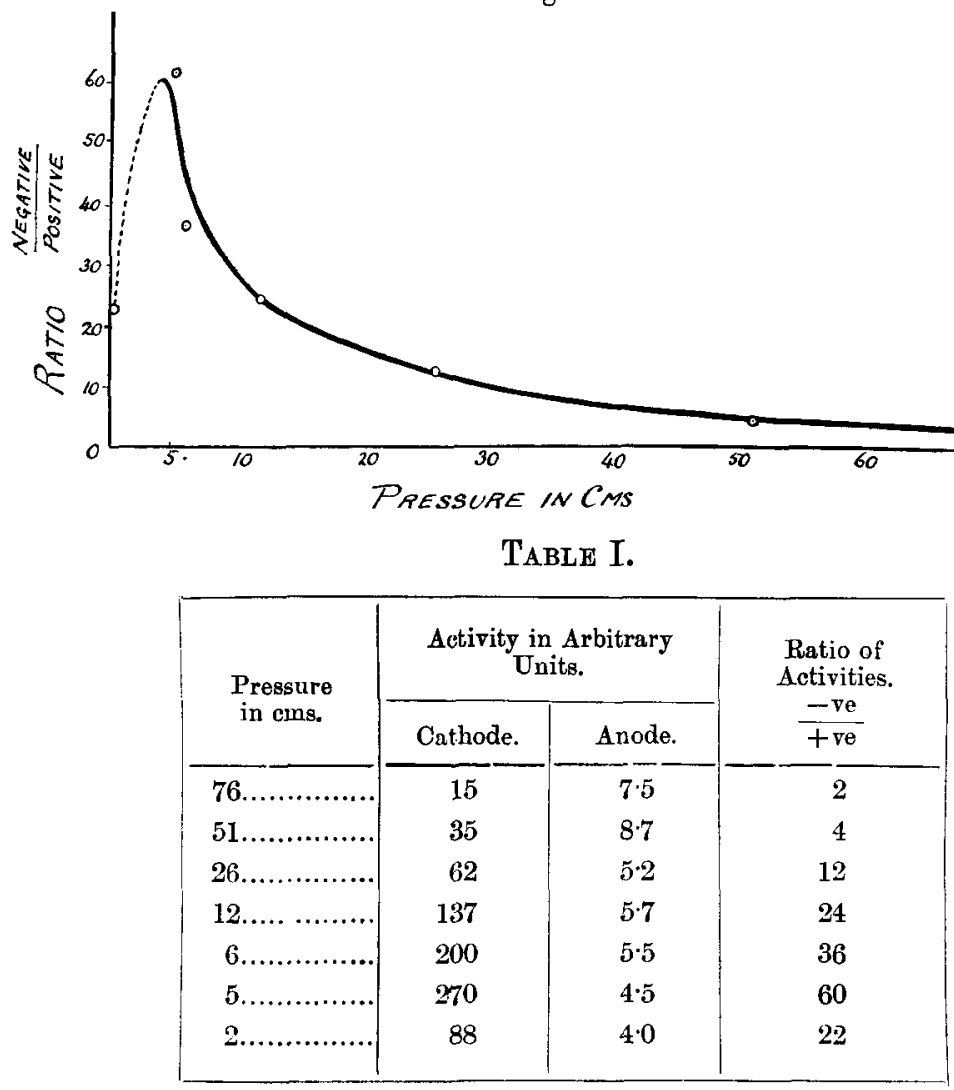

It will be observed that the ratio of the activities of the two wires increases steadily as the pressure is diminished, 
attaining a maximum value at about $5 \mathrm{cms}$. pressure, then falling abruptly at a pressure of about $\cdot 2 \mathrm{~cm}$.

Owing to the very short life of the emanation from actinium ( 3.9 seconds) the distribution of the emanation in the cylinder C must be very different at the different pressures employed. At atmospheric pressure the emanation, owing to its rapid change into actinium $A$, will be confined to a comparatively small region round $D$, and the active deposit particles will have a greater distance to go before reaching the wires $A$ and $B$ than at the reduced pressures. It is probable that the decrease in the ratio of the activity of the cathode to that of the anode between pressures of $5 \mathrm{cms}$. and $2 \mathrm{mms}$. corresponds to the similar effect with thorium which has been already mentioned.

It is worth noting that the activity observed on the anode is almost entirely due to some of the active deposit particles being negatively charged. This was shown as follows :An experiment was made in which no field existed between the wires and the containing cylinder, the activity observed on either of the wires was only about one-seventh part of that observed on the positive electrode. Hence the above conclusion.

At this stage it was resolved to vary the conditions of the experiment.

A preparation of actinium was placed at the bottom of a cylindrical vessel A (fig. 3) $9 \mathrm{cms}$. long and $4.5 \mathrm{cms}$. diameter,

Fig. 3.

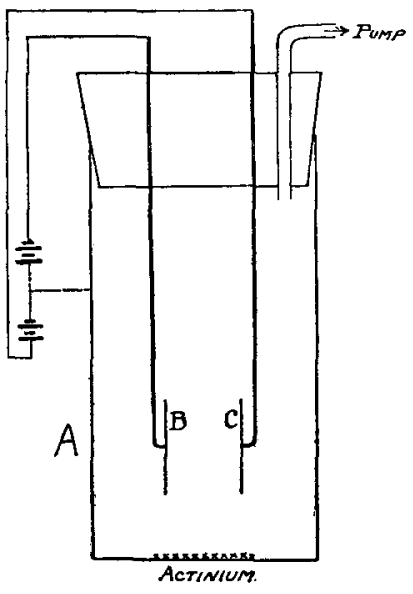

which was closed by a rubber stopper through which passed two brass rods carrying two vertical brass plates B and C; 
of the Active Deposit of Actinium.

the brass plates, $1.5 \mathrm{cms}$. apart, were fixed parallel to one another and connected to the terminals of a battery as before; and their distance from the actinium could be varied as required.

Two series of observations were made, at $76 \mathrm{~cm}$. and $2 \mathrm{mms}$. pressure, for different distances of the plates from the actinium. After an exposure of about two hours the plates were removed and their activities compared by means of an $\alpha$ ray electroscope.

The numerical results are collected in Table II., and the variation with distance of the ratio of the activity of the negative to that of the positive plate is reproduced graphically in fig. 4 (p. 742).

TABLE II.

\begin{tabular}{|c|c|c|c|c|}
\hline \multirow{2}{*}{\multicolumn{2}{|c|}{$\begin{array}{c}\text { Distance from } \\
\text { Actiniuu. }\end{array}$}} & \multicolumn{2}{|c|}{ Activity in Arbitrary Units. } & \multirow{2}{*}{$\begin{array}{c}\text { Ratio. } \\
\frac{-v e}{+v e}\end{array}$} \\
\hline & & Negative plate. & Positive plate. & \\
\hline & $76 \mathrm{cms}$. & Pressure. & & \\
\hline $.2 \mathrm{~cm}$. & ......... & 300 & 27 & 110 \\
\hline $4 \quad$, & & 250 & 30 & 83 \\
\hline 9 & .......... & 220 & $3 \cdot 1$ & 72 \\
\hline $1 \cdot 4$ & ......... & 200 & $4 \cdot 2$ & 48 \\
\hline $2 \cdot 2$ & ......... & 117 & $5 \cdot 4$ & 22 \\
\hline $2 \cdot \tau$ & ......... & 100 & $7 \cdot 7$ & 13 \\
\hline $4 \cdot 4$ & ......... & 14 & $5 \cdot 9$ & $2 \cdot 4$ \\
\hline $5 \cdot 0$ & .......... & 10 & $4 \cdot 3$ & $2 \cdot 3$ \\
\hline & 2 mms. & Pressure. & & \\
\hline$\cdot 2$ & ......... & 7.9 & $1 \cdot 6$ & $4 \cdot 9$ \\
\hline $1 \cdot 0$ & .......... & $7 \cdot 4$ & $1 \cdot 5$ & $4: 8$ \\
\hline $2 \cdot 2$ & .......... & $14 \cdot 1$ & $1 \cdot 3$ & $9 \cdot 6$ \\
\hline $4 \cdot 2$ & ......... & $22 \cdot 0$ & $1 \cdot 0$ & $22 \cdot 0$ \\
\hline
\end{tabular}

An inspection of the second and third columns of Table II. shows that at $76 \mathrm{cms}$. pressure, whereas the active matter deposited on the negative plate decreases as the distance of the plate from the actinium is increased, the amount obtained on the positive plate increases till a distance $2.7 \mathrm{cms}$. from the

Phil. Mag. S. 6. Vol. 15. No. 90. June 1908. 3 D 
actinium is reached, after which a diminution occurs, probably owing to the fact that the total quantity of active matter collected on the two plates is then very small.

At 2 mms. pressure the active matter obtained on the negative plate shows an increase as the plate is removed from the actinium, while the quantity on the anode shows a steady decrease.

Fig. 4.

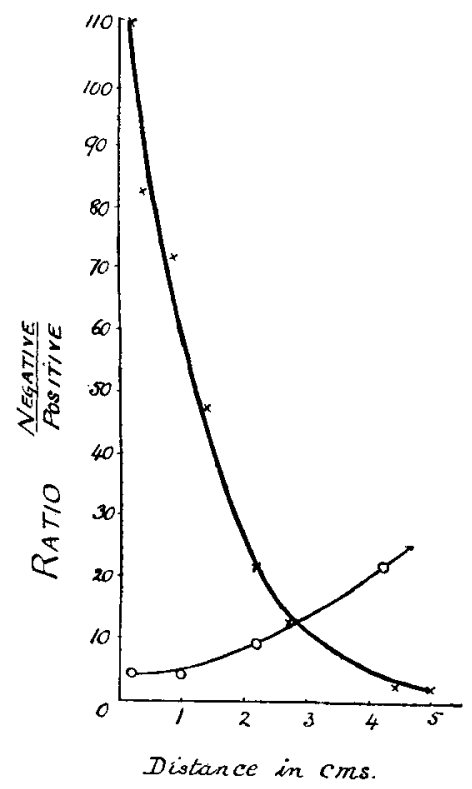

Crosses refer to $76 \mathrm{cms}$. pressure.

Circles refer to $2 \mathrm{mms}$. pressure.

It will be seen from fig. 4 that at atmospheric pressure the negative plate is more than one hundred times as active as the positive for small distances from the actinium, a very large diminution in the ratio resulting as the distance is increased. The opposite effect holds at a pressure of $2 \mathrm{mms}$.

It has been shown by Debierne* that the amount of emanation obtained from a uniform layer of actinium falls to half value on going $55 \mathrm{~cm}$. from the layer. We should, therefore, expect a diminution in the activity of the plates as their distance from the actinium is increased; but the

Le Radium,' 1907, p. 213. 
RATIO of the activities on the two plates should remain the same. This is, however, far from being the case, and moreover the positive plate shows signs of increased activity as its distance from the layer of actinium is increased. It appears then that in their passage through the containing gas, the positively charged active deposit particles may become neutralized, and in fact may even becomo reversed in sign. To account for the increase in the ratio observed at the low pressure, it must be remembered that at the moment of formation the active deposit particles have a very high velocity. Rutherford ${ }^{*}$ has suggested that a certain number of collisions may therefore be necessary to reduce their speed so that the electric field may be capable of directing them to the electrodes; hence as the distance of the plates from the actinium is increased at the low pressure, their total activity should increase, as is found to be the case.

It might be expected that if the distance of the plates from the actinium were made sufficiently large, even at the lower pressure, similar effects to those obtained at the high pressure would be observed. With the small cylinder described this was not possible; a larger one $40 \mathrm{cms}$. long and $7.5 \mathrm{cms}$. diameter was used, and experiments at an intermediate pressure $(1.2 \mathrm{cms}$.) were conducted in an exactly similar way to that already described.

The numerical data are collected in Table III. and reproduced graphically in fig. 5 .

TABLE III.

\begin{tabular}{|cc|c|}
\hline $\begin{array}{c}\text { Distance from } \\
\text { Actinium. }\end{array}$ & $\begin{array}{c}\text { Ratio of Activities. } \\
\text { Negative } \\
\text { Positive }\end{array}$ \\
\hline $1 \cdot 0 \mathrm{~cm}$. & $\ldots \ldots \ldots$. & 26 \\
3.5 & $\ldots \ldots \ldots$. & 44 \\
4.7 & $\ldots \ldots \ldots .$. & 62 \\
$9 \cdot 0$ & $\ldots \ldots \ldots$. & 76 \\
$11 \cdot 0$ & $\ldots \ldots \ldots$. & 82 \\
18.0 & $\ldots \ldots \ldots$. & 63 \\
$25 \cdot 7$ & $\ldots \ldots \ldots$. & 37 \\
30.5 & $\ldots \ldots \ldots .$. & 25 \\
\hline
\end{tabular}

* 'Radioactivity' p. 319.

$3 \mathrm{D} 2$ 
The amount of active deposit obtained on the plates decreased as their distance from the actinium was increased, but the rate of decrease was different for the two plates.

Inspection of the figure shows that at first there is an increase in the ratio of negative to positive activity as at the lower pressure, which subsequently shows a decrease similar to that observed at the high pressure.

Fig. 5.-1.2 cms, pressure.

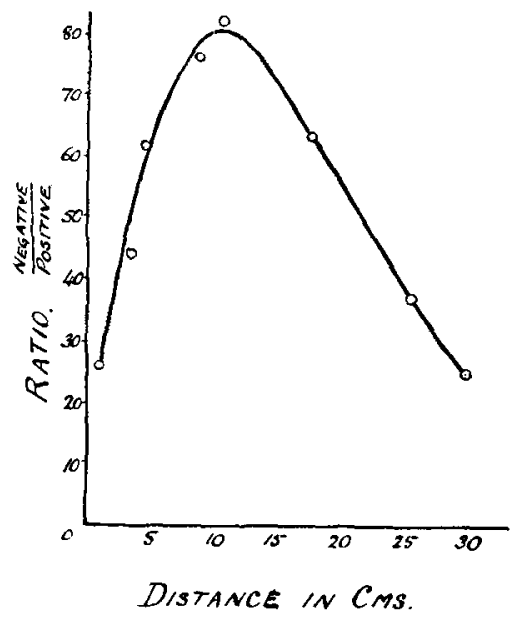

It must be noted that in the region between 11 and $18 \mathrm{cms}$. from the actinium it was impossible to obtain concordant results, sometimes a high and sometimes a low value for the ratio resulting.

It has been observed by Debierne in the paper already referred to, that there is a position of maximum activity in a vessel containing a preparation of actinium, but the writer does not know whether the experiments here described have any bearing on that point.

The question arises as to whether the apparent loss of the positive charge of the particles can be explained by their diffusion to the sides of the vessel, but considering the relatively small distance travelled necessary for the observed effects, it is difficult to see how loss by diffusion can account for them; moreover, it would not explain the marked increase in the activity of the positive plate in the experiments at atmospheric pressure. 
Conclusion.

It may be useful here to draw attention to some of the differences that have been observed in the transmission in electric fields of the active deposits of the different radioactive substances.

In dry and dust-free air at atmospheric pressure the active deposit of Thorium is almost completely confined to the negative pole ; on reduction of the gaseous pressure to a few mms. a marked diminution in the amount transmitted to the negative pole is observed, some of the active deposit then being found on the positive boundary of the system.

In the case of Radium the transmission of its active deposit to the negative pole is not so complete as with thorium ; at atmospheric pressure about 95 per cent. of the active deposit is directed to the negative pole, the remaining 5 per cent. going to the positive pole. With reduction of the gaseous pressure similar effects are observed to those mentioned for thorium, the activity of the negative boundary decreasing, that of the positive increasing.

With Actinium the active deposit may at atmospheric pressure be almost completely directed to the negative pole, but by suitable variation of the experimental conditions, the distribution may be rendered much less complete, the amount obtained on the negative pole being reduced to as little as twice that on the positive.

At low pressures, there is the same possibility of the phenomena observed depending on experimental conditions.

From the results of several independent observers it seems clear that the electrical charge exhibited by the active deposit particles of the radioactive substances is mainly determined by the numerous collisions between these particles and the ions or molecules of the gas with which they are mixed.

Whether the active deposits are electrically charged at the moment of formation from the emanations, still remains an open question. Although experiments with the active deposit from Radium show that at very low pressures (about $01 \mathrm{~mm}$.) almost as much is directed to a positive as to a negative pole, this does not preclude the possibility of the active deposit particles being really positively charged, for at this pressure the velocity of the particles is so high that no ordinary electric field would be capable of directing them to the negative boundary of the system. 